\title{
Computer (and Human) Perfection at Checkers
}

\author{
Jonathan Schaeffer \\ Department of Computing Science \\ University of Alberta
}

\begin{abstract}
In 1989 the Chinook project began with the goal of winning the human World Checkers Championship. There was an imposing obstacle to success ?the human champion, Marion Tinsley. Tinsley was as close to perfection at the game as was humanly possible. To be better than Tinsley meant that the computer had to be perfect. In effect, one had to solve checkers. Little did we know that our quest would take 18 years to complete. What started out as a research project quickly became a personal quest and an emotional roller coaster. In this talk, the creator of Chinook tells the story of the quest for computer perfection at the game of checkers.
\end{abstract}

